\title{
ANALYSIS OF THE AETIOLOGY AND SYMPTOMATICS OF THE CLINICAL CASE OF TONSILITE
}

\section{Yuliia Pefti $^{1}$ \\ Oleh Fedotov $^{2}$}

DOI: https://doi.org/10.30525/978-9934-588-39-6-28

Tonsillitis occupies a leading place in upper respiratory tract pathology in both adults and children. But in the infant population, acute tonsillitis is more common, while among adults it is chronic. The chronic course in the adult group is most often associated with multiple cases of improperly treated acute tonsillitis. In some cases of an adult group of diseases, tonsillitis can develop on its own, ie be primary [3, p. 36; 5, p. 9-12].

The aim of the study was to analyze the etiology, symptomatology and clinical case of tonsillitis.

Common methods of data analysis and clinical case description of tonsillitis diagnosis and treatment were used.

Acute, tonsillitis is known to be a disease with acute inflammation of one or more lymphoid formations of the pharyngeal ring (more often the palatine almond). However, lymphoid pharyngeal ring formation (even hyperplasia) continues to play a significant role in the functioning of the immune system [3, p. 37; 4, p. 80-81].

Among bacterial pathogens of acute tonsillitis and pharyngitis, $\beta$-hemolytic group A streptococcus is of the greatest importance. Also, acute tonsillitis is caused by group C and G streptococci, Arcanobacterium haemolyticum, Neisseria gonorrhoeae, Corynebacterium diphtheriae, anaerobes and spirochetes, rarely mycoplasma and chlamydia. The causes of viral acute pharyngitis and tonsillitis are adenoviruses, rhinovirus, coronavirus, influenza and parainfluenza viruses, Epstein-Barr virus (VEB), Coxsackie A. It is believed that viral forms of acute tonsillitis are prevalent in children under 3 years (70-90\%), after 5 years bacterial forms (up to 30-50\%) [1, p. 324-325; 2, p. 90; 4, p. 82].

With the exception of single cases, acute tonsillitis is accompanied by fever to subfebrile or febrile numbers, sore throat, swallowing problem, loss of appetite, hyperemia of the mucous membrane of the tonsils and purulent layers on them, enlargement and pain of lymph nodes, partial temporary hearing loss, etc [5, p. 231-234].

\footnotetext{
${ }^{1}$ Donetsk National Medical University, Ukraine

${ }^{2}$ Donetsk National Medical University, Ukraine
} 
Morphological changes in acute tonsillitis are characterized by swelling and infiltration of the cellular elements of the mucous membrane, vasodilation, and desquamation of the epithelium. The inflammatory response is usually more pronounced in areas of lymphoid tissue accumulation - in the area of the nasopharynx, near the mouth of the auditory tubes, in the tonsils, on the posterior and lateral walls of the pharynx [5, p. 74].

On clinical examination, hyperemia, edema, injection of the vessels of the mucous membrane and purulent layers on the surface of the tonsils are determined.

Even today, chronic tonsillitis therapy remains a rather complex and urgent problem in the daily practice of otolaryngologists, family physicians, clinical immunologists.

Environmental pollution, constant aggression of pollutants, frequent unjustified use of antibiotics cause an annual increase in the incidence of chronic inflammatory processes of the respiratory system, including in Mariupol [2, p. 90-91].

In the course of the study, it was also interesting to confirm the analysis of scientific literature data by studying the course of diagnosis and treatment of tonsillitis on the example of a clinical case.

Thus, the age of patient $\mathrm{X}$, whose personal data were used in the course of scientific work, is 11 full years. His parents went to the city hospital № 1, Mariupol city. The patient had the following symptoms: frequent sore throats (three or more times a year), the last time sore throat was a month ago, periodic hearing loss in the right and left ear for 6 months, transfer of paratonsillary abscess. At the same time, conservative treatment in outpatient establishments was ineffective throughout the year. The general condition of the patient is satisfactory, lymph nodes are not enlarged, breathing of the lungs is vesicular, there are no wheezing, allergoamnesis is not burdensome.

The following studies were performed by the doctor to establish an accurate diagnosis of ENT. Rhinoscopy. Its results are: the mucous membrane of the nose is pink, the nasal breathing is free, the nasal septum is in the middle, the lower nasal cones are regular in shape, breathing with the nose is free. Otoscopy. Its results: the ears shells of the correct form, the auditory passages are not changed, the tympanic membranes are blue, the fluid is visualized at the endoscopic examination of the tympanic membranes. Oropharyngoscopy. Its results are: mucous membrane of the mouth, pharynx of normal color; palatine tonsils hypertrophied, lacustrine caseous masses; when rotating the tonsils from the lacunae, liquid pus is released.

ENT doctor was diagnosed with chronic decompensated tonsillitis. It was decided to resort to surgery. 
The operation was performed under general anesthesia. After the rotator expander was installed, a section of the mucosa along the edge of the anterior palatal brace was made. The blunt path alternately cut off both tonsils. Single formations are dissected with scissors. During the operative work there was moderate bleeding, which was stopped before the end of the operation. At otomicroscopy in the posterior-inferior third of the middle ear, an incision of the eardrum was made according to the size of the shunts. Shunts are inserted with earplugs. On this surgery was ended and the patient was transferred to the ward.

After ten days of medical supervision, the patient was discharged with the following symptoms: no complaints were filed; nasal mucosa pink, clear; mucous pharynx pink, in the lacunae of the film in a small amount, mouth opening is free; epiglottis not changed; true voice communications whitish, mobile, symmetrical; breathing is free; the voice is audible.

In addition, recommendations were made: for a scheduled postoperative examination at the operating surgeon one week after discharge, as well as warning of water getting into your ear.

For the prevention of tonsillitis it was recommended: to provide the child with clean, not overheated (up to $20^{\circ} \mathrm{C}$ ) air in the bedroom, spend at least 2 hours in the open air; use less refined food; consult your doctor in time for certain symptoms.

Thus, the analysis of the etiology, symptomatology and clinical case of the tonezilitis of the patient in childhood, allows us to draw the following conclusions. First, the treatment of chronic tonsillitis even today remains quite a complex and urgent problem in the daily practice of otolaryngologists, family doctors, clinical immunologists. Secondly, environmental pollution, constant aggression of pollutants, frequent unjustified use of antibiotics cause an annual increase in the incidence of chronic inflammatory processes of the respiratory system. Third, inflammatory diseases of the upper respiratory tract are desirable (unless otherwise indicated) to be treated therapeutically and, if possible, not to lead to surgery. Fourth, if patients have problems with the tonsils, it is better to operate them in infancy - where greater therapeutic efficacy is achieved, including a rapid postoperative healing process.

\section{References:}

1. Abazi B., Shaqiri B., Ajvazi H., \& Lutaj P. (2015). Clinical Impact of Chronic Tonsillitis on Weight and Height Parameters. Med. Arch., vol. 69, no. 5, pp. 323-326.

2. Hoshko, K. O., Malenko, K. A., \& Fedotov, O. V. (2020). Studying the importance of visualization methods and comprehensive oral cavity sanitation as a factor of prevention of intensifying the development of dental diseases. Scientific achievements of modern society. Abstracts of the 7th International scientific and practical conference. Cognum Publishing House. Liverpool, United Kingdom, pp. 90-94. 
3. Kosakovsjkyj A. L., \& Ghavrylenko Ju. V. (2014). Suchasnyi pidkhid do likuvannia hostroho ta khronichnoho adenoidytu $\mathrm{v}$ ditei [A modern approach to the treatment of acute and chronic adenoiditis in children]. Ukrainian Medical Journal, vol. 2, no. 100, pp. 36-40. (in Ukrainian)

4. Krjuchko T. F. (2010). Problema tonzillita v pediatricheskoy praktike [The problem of tonsillitis in pediatric practice]. Child health, no. 1, pp. 79-82. (in Russian)

5. Lajko, A. A., Kosakovsjkyj, A. L., \& Zabolotna, D. D. (2013). Dytiacha otorynolarynholohiia [Pediatric otolaryngology]. Kyiv: Logos, 575 p. (in Ukrainian) 